\title{
Phosphoinositide 3-Kinase (PI3K) Activation is Differentially Regulated during Osteogenesis induced by TGF- $\beta 1$ and BMP-2/BMP-7
}

\author{
Haruto Yamashita ${ }^{1)}$, Hiromi Ochiai ${ }^{2,3)}$, Akiko Saito ${ }^{2,3)}$, Seikou Shintani ${ }^{1)}$ and Toshifumi Azuma ${ }^{2,3)}$ \\ ${ }^{1)}$ Department of Pediatric Dentistry, Tokyo Dental College, Tokyo, Japan \\ 2) Department of Biochemistry, Tokyo Dental College, Tokyo, Japan \\ 3) Oral Health Science Center hrc8 (hrc8), Tokyo Dental College, Tokyo, Japan \\ (Accepted for publication, October 4, 2013)
}

\begin{abstract}
Periodontal ligament (PDL) cells are comprised of heterogenous cell populations including mesenchymal stem cells and osteogenic progenitor cells. We previously reported that differentiation of human PDL cells into osteoblasts requires phosphoinositide 3-kinase (PI3K) activities. Here, we investigate osteoblast differentiation using TGF- $\beta 1$, BMP-2/BMP-7, and dexamethasone (Dex) in human PDL cells, focusing on the $\mathrm{PI} 3 \mathrm{~K} / \mathrm{Akt}$ pathway. We found that in TGF- $\beta 1$-treated cells, Dex increased IGF-1 expression as well as phosphorylated Akt, which is a main target molecule of PI3K. Downregulation of IGF-1 expression and enhanced phosphorylation of Akt were observed in BMPs with Dex-treated cells, even though alkaline phosphatase expression and activities were enhanced. These results indicate that IGF-1 is a key regulator in TGF- $\beta 1$-induced osteogenesis, but it is not required in osteoblast differentiation initiated by BMPs. Because BMPs require PI3K activation for osteoblast differentiation, and because BMP treatment upregulates Akt phosphorylation, signaling molecules other than IGF-1 may support BMP-induced osteoblast differentiation.
\end{abstract}

Key words: Transforming growth factor- $\beta 1$, Bone morphogenetic protein-2/-7, Phosphoinositide 3-kinase, Osteoblast differentiation

\section{Introduction}

The periodontal ligament (PDL) is a connective tissue consisting of heterogeneous population which includes undifferentiated mesenchymal cells, osteoprogenitors, fibroblasts and cementoblasts. Cells in PDL exhibit the potential to differentiate into osteoblasts in vitro ${ }^{1}$. Some studies reported that human PDL contains stem cells and consequently PDL stem cells have the potential to generate cementum/PDL-like tissue ${ }^{2,3)}$. Therefore, PDL is featured as a useful source of regenerative therapy.

Bone morphogenetic proteins (BMPs) are multi-functional growth factors that belong to the TGF- $\beta$ family. They play a pivotal role in connective tissue regeneration and bone remodeling. Previous reports demonstrated that BMP has significant effects in osteogenic differentiation and bone formation. In particular, BMP-2 and BMP-7 can strongly induce osteogenesis of bone marrow mesenchymal stem cells ${ }^{4-6)}$. Furthermore, BMP-2/-7 heterodimers are usually the most potent osteogenic inducers ${ }^{7}$. Transforming growth factor (TGF) $-\beta 1$ is crucial for connective tissue regeneration and bone remodeling, as demonstrated by

Correspondence to: Dr. Toshifumi Azuma, Department of Biochemistry, Tokyo Dental College, 2-9-18 Misakicho, Chiyoda-ku, Tokyo, 101-0061 Japan; Tel: +81-3-6380-9263; E-mail: tazuma@tdc.ac.jp several in vivo and in vitro studies ${ }^{8-12)}$. TGF- $\beta 1$ increases mRNA levels of osteoblast differentiation markers and alkaline phosphatase (ALP) activity in murine bone marrow stromal cells ${ }^{11}$. However, TGF- $\beta 1$ also blocks osteogenesis by various mechanisms depending on its concentration, the cell density, and differentiation stage of the cells ${ }^{13}$. Some studies reported that TGF$\beta 1$ has biphasic and concentration-dependent effects on osteoblast differentiation ${ }^{14-16)}$. We recently reported that repetitive TGF- $\beta 1$ administration negatively regulated osteoblast differentiation by down-regulation of Insulin-like growth factor-1 (IGF-1) production ${ }^{17}$. IGF-1 is one of the most abundant cytokines in bones and supposed to play an important role in osteogenesis. Indeed, IGFs stimulate in vitro and in vivo osteoblast proliferation and differentiation through specific membrane receptors ${ }^{18-21)}$. Although IGF-1 does not direct undifferentiated stromal cells to differentiate into cells of an osteoblast lineage, it enhances the function of mature osteoblasts ${ }^{22}$. Synthetic glucocorticoid dexamethasone (Dex) is generally a useful reagent for osteoblast differentiation ${ }^{23)}$. However, it has both stimulatory and inhibitory effects on osteoblast differentiation depending upon the dose, duration, stage of cell differentiation and species of responding cell $^{24)}$.

The differentiation mechanism of the stem cells in oral tissue 
Table 1. Primer and Probe Sets for Quantitative Real-Time PCR Analysis

\begin{tabular}{|c|c|c|c|c|}
\hline Gene Symbol & Gene Bank accession no. & Primer sequence: sense/antisense & Probe no. & Amplicon \\
\hline ALP & NM_000478.3 & $\begin{array}{l}\text { 5'-caaccctggggaggagac-3' } \\
\text { 5'-gcattggtgttgtacgtcttg-3' }\end{array}$ & $\# 19$ & $78 \mathrm{bp}$ \\
\hline IGF-1 & NM_000618.3 & $\begin{array}{l}\text { 5'-tgtggagacaggggctttta-3, } \\
\text { 5'-atccacgatgcctgtctga-3' }\end{array}$ & $\# 67$ & $84 \mathrm{bp}$ \\
\hline PAPP-A & NM_002581.3 & $\begin{array}{l}\text { 5'-aaccccacacgggtagaga-3' } \\
\text { 5'-agagcagggtgaggatacca-3' }\end{array}$ & \#54 & $65 \mathrm{bp}$ \\
\hline 18s rRNA & M11188.1 & $\begin{array}{c}5 \text { '-cggacaggattgacagattg-3, } \\
5 \text { '-cgctccaccaactaagaacg-3, }\end{array}$ & $\# 77$ & $78 \mathrm{bp}$ \\
\hline
\end{tabular}

has remained unclear although stem cells are attractive candidates for clinical application. And it is not clear that the combination of TGF- $\beta 1$ and Dex or BMP-2/-7 and Dex can stimulate osteoblast differentiation in PDL cells. In this study, we investigated that whether combination of TGF- $\beta 1$ and Dex or BMP-2/-7 and Dex associate with IGF-1 expression and stimulate osteoblast differentiation.

\section{Materials and Methods Cell culture and osteogenic differentiation}

Human periodontal ligament (HPDL) cells were purchased from Lonza (Basel, Switzerland) and cultured in BulletKit ${ }^{\circledR}$ Stromal cell growth medium (SCGM) (Lonza, Basel, Switzerland). HPDL cells of passages 5 to 8 were seeded at a density of $1 \times 10^{5}$ cells $/ \mathrm{cm}^{2}$ for each assay. Osteoblast differentiation was induced by replacing with the osteoblast differentiation medium (OBM), comprising $\alpha$-MEM (Invitrogen, Carlsbad, CA, USA) supplemented with $50 \mu \mathrm{g} / \mathrm{mL}$-ascorbic acid (Wako Pure Chemical Industries Ltd., Osaka, Japan) and $10 \mathrm{mM} \beta$-glycerophosphate (Wako,Tokyo,JAPAN), 1 ng/mL rhTGF- $\beta 1$ (Wako, Tokyo, Japan), $50 \mathrm{ng} / \mathrm{mL}$ BMP-2/-7 (R\&D Systems, MN, USA), and $10 \mathrm{nM}$ dexamethasone (Sigma-Aldrich, St. Louis, MO, USA), they were added on the following day. Under the single TGF- $\beta 1$ or BMP-2/ -7 administration condition, the medium was not changed until 72 hours, whereas under repeated TGF- $\beta 1$ administration condition, OBM containing fresh TGF- $\beta 1$ was changed after 12 hours. Control cells were treated identically except that they did not receive TGF- $\beta 1$, BMP-2/-7 and dexamethasone.

\section{Alkaline phosphatase (ALP) staining}

Seventy two hours after stimulation, cells were washed two times with phosphate-buffered saline (PBS), fixed with $4 \%$ paraformaldehyde for 5 minutes at room temperature, and washed three times with distilled water. For staining, an ALP substrate solution (Roche Diagnostics, Basel, Switzerland) was added to the fixed cells for 60 minutes at room temperature. After staining, cells were washed three times with distilled water and images were scored.

\section{Quantitative real time-PCR}

Real time-PCR was used to examine the expression of osteoblast differentiation markers. After incubating for 72 hours in the differentiation medium, total RNA was extracted from cultured cells by using QIAzol reagent (Qiagen Inc., Valencia, CA, USA) according to the manufacturer's instructions. cDNA was synthesized using a high-capacity cDNA reverse transcription kit (Applied Biosystems, Foster City, CA, USA). Real time-PCR analysis was performed using the Premix Ex Taq ${ }^{\mathrm{TM}}$ reagent (Takara Bio Inc., Shiga, Japan) according to the manufacturer's instructions. Target genes included alkaline phosphatase (ALP), insulin-like growth factor 1 (IGF-1) and Pregnancy-associated plasma protein-A (PAPP-A).

18S rRNA was used as an internal control. All primers and probes are presented in Table. 1 was designed using Probefinder v2.45 (http://qpcr.probefinder.com/roche3.html).

\section{Protein extraction and immunoblotting}

Cells were lysed with lysis buffer (10 mM Tris- $\mathrm{HCl} \mathrm{pH}$ 7.5, $150 \mathrm{mM} \mathrm{NaCl}$, complete protease inhibitor mixture, $1 \mathrm{mM}$ sodium orthovanadate, and $1 \% \mathrm{NP}-40$ ), and the protein content was measured using a DC Protein Assay Kit (Bio-Rad, Marnes-laCoquette, France). Equivalent protein concentrations were resolved by electrophoresis on NuPAGE $4 \%-12 \%$ Bis-Tris gels (Invitrogen) and transferred to a PVDF membrane. The membrane was probed with anti-phosphorylated Akt (1:2000; Cell Signaling Technology Inc., Danvers, MA, USA) and anti-IGF-1 (1:2500; Abcam, Cambridge, UK) antibodies, followed by HRP-conjugated goat anti-rabbit IgG. Bound antibodies were visualized using a chemiluminescent substrate (ECL plus; GE Healthcare UK Ltd., Buckinghamshire) and ImageQuant LAS $4000 \mathrm{mini}$ (GE healthcare).

\section{Statistical analysis}

All data are expressed as mean \pm S.D. When ANOVA indicated differences among the groups, multiple comparisons between each experimental group were performed using the Bonferroni test. Statistical significance was defined as $p<0.05, p<0.001$. 
A

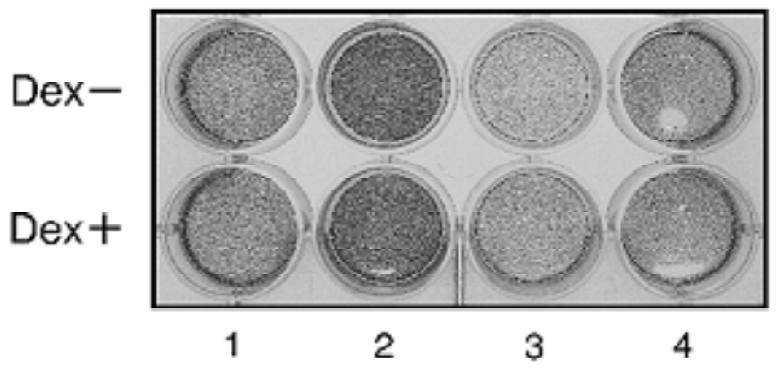

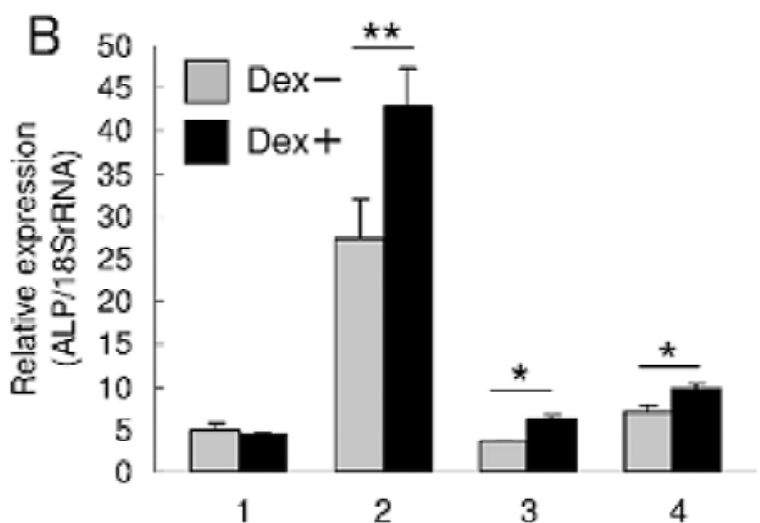

Figure 1. The effect of TGF- $\beta 1$, BMP-2/-7 and Dex on osteoblast differentiation of HPDL cells. Confluent HPDL cells were cultured in OBM (1), OBM with a single administration of $1 \mathrm{ng} / \mathrm{mL}$ TGF- $\beta 1$ (2), OBM with repeated administration of $1 \mathrm{ng} / \mathrm{mL}$ TGF- $\beta 1$ (3), and OBM with a single administration of $50 \mathrm{ng} / \mathrm{mL} \mathrm{BMP-2/-7} \mathrm{(4)} \mathrm{for} 72 \mathrm{~h}$. (A) ALP activity was visualized by ALP activity staining of cells. Single treatment with TGF- $\beta 1$ was more induced ALP expression compared to BMP-2/-7 treatment. Repeated administration with TGF- $\beta 1$ markedly suppressed ALP expression. (B) Addition of Dex to TGF- $\beta 1$ or BMP-2/-7 more upregulated ALP mRNA expression than TGF- $\beta 1$ or BMP-2/-7 alone. Expression of this gene was analyzed by qRT-PCR and their mRNA levels were normalized to that of $18 \mathrm{~S}$ rRNA. Each experiment was performed in triplicate, and the data represent the means \pm S.D. $(n=4)$. Bonferroni correction for multiple comparisons was applied. " $p<0.05,{ }^{* *} p<0.001$.

A

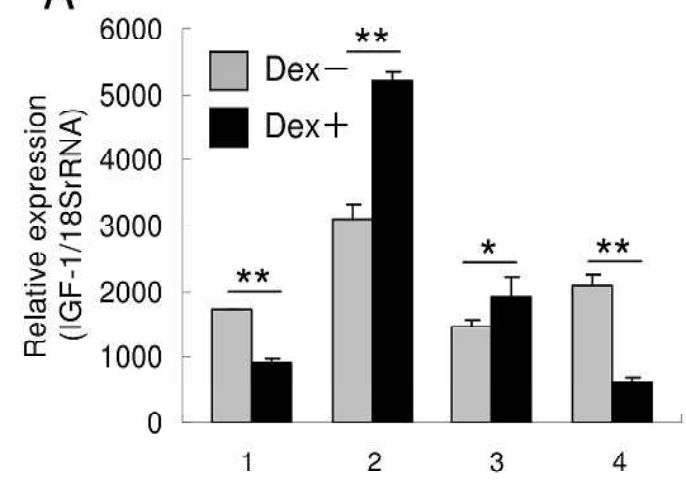

B

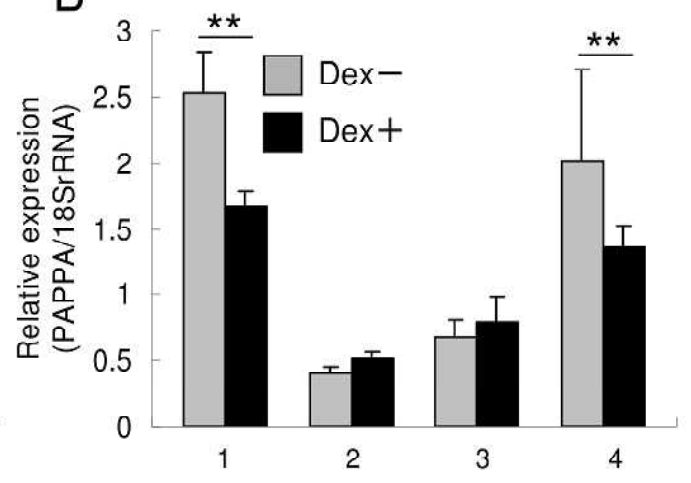

Figure 2. mRNA expression levels of IGF-1 and PAPP-A by Dex addition in TGF- $\beta 1$ or BMP-2/-7 treated cells. Confluent HPDL cells were cultured in OBM (1), OBM with a single administration of $1 \mathrm{ng} / \mathrm{mL}$ TGF- $\beta 1$ (2), OBM with repeated administration of $1 \mathrm{ng} / \mathrm{mL}$ TGF- $\beta 1$ (3), and OBM with a single administration of $50 \mathrm{ng} / \mathrm{mL}$ BMP-2/-7 (4) for $72 \mathrm{~h}$. (A) In TGF- $\beta 1$ treatment, IGF-1 mRNA expression was more induced by Dex addition. IGF-1 mRNA expression was significantly suppressed by Dex addition in BMP-2/-7 treatment cells. (B) PAPP-A mRNA expression was decreased in BMP-2/-7 treatment cells by Dex addition. Expression of these genes was analyzed by qRTPCR and their mRNA levels were normalized to that of $18 \mathrm{Sr}$ RNA. Each experiment was performed in triplicate, and the data represent the means \pm S.D. $(\mathrm{n}=4)$. Bonferroni correction for multiple comparisons was applied. ${ }^{* *} p<0.001$.

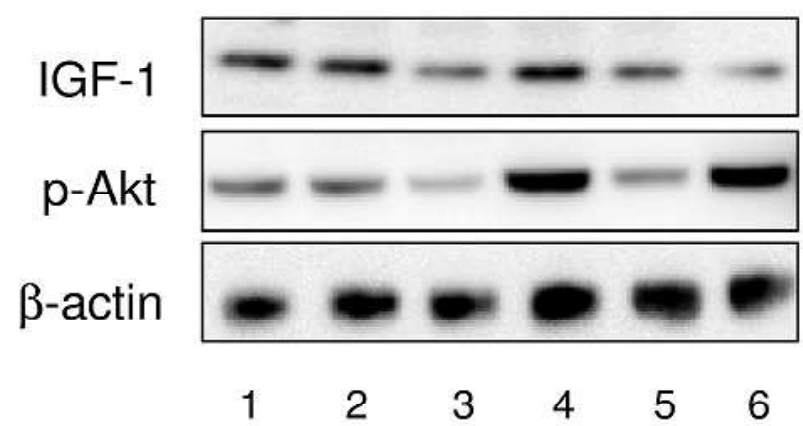

Figure 3. The levels of IGF-1 protein and phosphorylated Akt protein by Dex addition in TGF- $\beta 1$ or BMP-2/-7 treated cells. Confluent HPDL cells were cultured in OBM (1), OBM with a single administration of $1 \mathrm{ng} /$ $\mathrm{mL}$ TGF- $\beta 1$ (2), OBM with repeated administration of $1 \mathrm{ng} / \mathrm{mL}$ TGF- $\beta 1$ (3), OBM containing $10 \mathrm{nM}$ Dex with repeated administration of $1 \mathrm{ng} /$ $\mathrm{mL}$ TGF- $\beta 1$ (4), OBM with a single administration of $50 \mathrm{ng} / \mathrm{mL} \mathrm{BMP-2/}$ -7 (5), and OBM containing $10 \mathrm{nM}$ Dex with a single administration of $50 \mathrm{ng} / \mathrm{mL} \mathrm{BMP-2/-7} \mathrm{(6)} \mathrm{for} 72 \mathrm{~h}$. The levels of IGF-1 protein and phosphorylated Akt were determined by Western blot analysis. A single TGF- $\beta 1$ administration markedly increased IGF- 1 and $p$-Akt protein level compared to BMP-2/-7 administration. Repeated TGF- $\beta 1$ treatment significantly decreased IGF-1 and p-Akt protein level. TGF- $\beta 1$ treatment with Dex increased IGF-1 protein level. However, BMP-2/-7 treatment with Dex remarkably inhibited IGF-1 protein level. Dex addition significantly increased p-Akt protein level in both TGF- $\beta 1$ and BMP-2/7 treatment. Blots are performed in triplicate. 


\section{Results \\ mRNA expression of ALP and ALP activity staining}

As shown in Fig. 1A, single treatment with TGF- $\beta 1$ was more induced ALP expression, an early mineralization marker indicating commitment to osteoblast differentiation, compared to BMP-2/-7 treatment. Repeated treatment with TGF- $\beta 1$ markedly suppressed ALP expression. Addition of Dex to TGF- $\beta 1$ or BMP-2/-7 more upregulated ALP mRNA expression than TGF- $\beta 1$ or BMP- $2 /-7$ alone (Fig. 1B).

\section{mRNA expression of IGF-1 and PAPP-A}

In TGF- $\beta 1$ treated cells, IGF- 1 mRNA expression was more induced by Dex addition (Fig. 2A). However, IGF-1 mRNA expression was significantly suppressed by Dex addition in BMP2/-7 treated cells (Fig. 2A). Similarly, PAPP-A mRNA expression was decreased in BMP-2/-7 treatment cells by Dex addition (Fig. 2B).

\section{Expression of IGF-1 and p-Akt protein}

As shown in Fig. 3, IGF-1 protein level in TGF- $\beta 1$ treatment cells was higher than BMP-2/-7 treatment. Repeated TGF- $\beta 1$ administration significantly decreased IGF-1 protein level. Dex addition increased IGF-1 protein level in TGF- $\beta 1$ treated cells. However, in cells treated with BMP-2/-7, Dex inhibited the IGF1 protein level as shown in repeated TGF- $\beta 1$ administration group. Similarly, the protein level of $\mathrm{p}$-Akt, a downstream effector of PI3K, in TGF- $\beta 1$-treated cells was higher than in cells treated with BMP-2/-7. Akt phosphorylation was dramatically reduced after repeated TGF- $\beta 1$ treatment. Dex addition significantly augmented the p-Akt protein level in both TGF- $\beta 1$-treated and BMP-2/-7-treated cells.

\section{Discussion}

In this article, we describe that Dex combined with BMP-2/7-induced osteoblast differentiation of HPDL cells independently of IGF-1 expression, although Dex combined with TGF- $\beta 1$ induced osteoblast differentiation associated with IGF-1 expression.

IGF-1 is expressed by osteoblasts and has modest effects on the proliferation of cells of the osteoblast lineage. IGF-1 enhances the function of the mature osteoblasts, although IGF-1 does not direct the differentiation of undifferentiated stromal cells toward cells of the osteoblast lineage. The IGF-1 gene knockout mice revealed that the fetal mice demonstrated short-limb dwarfism delays in mineralization and increased chondrocyte apoptosis ${ }^{25)}$. The combined delivery of BMP-7 and IGF-1 genes synergistically enhanced the differentiation of HPDL cells while suppressing their proliferation $^{21)}$. We previously reported that a single low dose of TGF- $\beta 1$ treatment promoted osteoblast differentiation whereas treatment with repetitive low doses, or a single high dose, of TGF- $\beta 1$ had much weaker effects in osteoblast differentiation. Moreover, we found that this osteogenesis by TGF- $\beta 1$ is caused by IGF-1 production. Inhibition of IGF-1 signaling using small interfering RNA (siRNA) against insulin receptor substrate-1 (IRS1) suppressed mRNA expression of RUNX2, ALP, BSP, and IGF1 even with single TGF- $\beta 1$ administration. Exogenous and overexpressed IGF-1 recovered ALP activity and mRNA expression of osteoblast differentiation marker genes even with repeated TGF- $\beta 1$ administration. Thus, IGF-1 plays a central role of osteoblast differentiation ${ }^{13)}$.

BMP-2, an agent that enhances osteoblast differentiation and function, increases IGF-1 synthesis in osteoblasts ${ }^{26)}$. The synthetic glucocorticoid Dex is generally a useful reagent for osteoblast differentiation ${ }^{23)}$. However, it has both stimulatory and inhibitory effects on osteoblast differentiation depending upon the dose, duration, stage of cell differentiation and species of responding cell $^{24,27}$. At the same time, it is catabolic factor inducing bone loss or osteoporosis with prolonged administration in human system ${ }^{28}$. Sun et al. reported that Dex decreased mRNA expression of ALP and $\alpha 2$ (I) collagen in mouse dental papillae cell line MDPC$23^{29)}$. We therefore investigated the effect of Dex on osteoblast differentiation induced by TGF- $\beta 1$ or BMP-2/-7 in HPDL cells since Dex has biphasic effects on osteoblast differentiation by various conditions such as Dex concentration and cell types.

Both TGF- $\beta 1$ and BMP-2/-7 were capable of inducing osteoblast differentiation of HPDL cells, and TGF- $\beta 1$ was higher in its potency than BMP-2/-7 (Fig. 1). Dex combined with TGF$\beta 1$ and BMP-2/-7 increased ALP mRNA expression. IGF-1 production play a central role in TGF- $\beta 1$-induced osteoblast differentiation. Dex combined with TGF- $\beta 1$ increased IGF-1 expression compared to TGF- $\beta 1$ alone. However, BMP-2/-7 with Dex treatment suppressed IGF-1 mRNA expression and protein production and PAPP-A mRNA expression compared to BMP-2/ -7 alone (Figs. 2 and 3). PAPP-A is a matrix metalloprotease which specifically cleaves IGF binding protein (IGFBP)-2, $-4,-5$ and increases IGF-1 bioavailability ${ }^{30)}$. These results suggest that the mechanism of BMP-2/-7-induced osteoblast differentiation of HPDL cells may differs from that of TGF- $\beta 1$. Therefore, TGF- $\beta 1$ regulates osteoblast differentiation via IGF-1 production, BMP2/-7 may regulate through IGF-1 along with alternative mechanisms.

$\mathrm{PI} 3 \mathrm{~K} /$ Akt pathway is known that IGF-1 activates this pathway and play an important role in cellular growth, differentiation and metabolism. Repeated TGF- $\beta 1$ treatment markedly inhibited IGF1 expression and subsequently Akt phosphorylation (Fig. 3). These results suggest that the inhibition of osteoblast differentiation caused by repeated TGF- $\beta 1$ treatment is associated with the downregulation of IGF-1 expression and Akt inactivation. As shown in Fig. 3, p-Akt was markedly increased by Dex addition in TGF- $\beta 1$ and BMP-2/-7 treated cells. It is thought that Dex could 
Haruto Yamashita et al:: TGF- $\beta$ Family cytokines on Signal Transduction in Osteoblastic Cells

pass a cell membrane easily and then arrive at the nucleus, and finally transmit every signal because it is a steroidal hormone. Therefore, in BMP-2/-7 treatment cells Dex addition could induce osteoblast differentiation such as up-regulation of ALP mRNA expression independently of IGF-1 production.

In conclusion, Dex combined with TGF- $\beta 1$ promotes osteoblast differentiation via IGF-1 expression. However, unlike TGF- $\beta 1$, Dex combined with BMP-2/-7 promotes osteoblast differentiation independently of IGF-1 expression. We suggest that although TGF- $\beta 1$ and BMP-2/-7 belong to the same TGF- $\beta$ family and have an ability to induce the osteoblast differentiation, the mechanism of osteoblast differentiation is different. Further studies of Dex combined with these cytokine will help to clarify the osteoblast differentiation of HPDL cells and possibly lead to the development of novel bone-forming drug.

\section{References}

1. Zhou Y, Hutmacher DW, Sae-Lim V, Zhou Z, Woodruff M and Lim TM. Osteogenic and adipogenic induction potential of human periodontal cells. J Periodontol 79: 525-534, 2008

2. Seo BM, Miura M, Gronthos S, Bartold PM, Batouli S, Brahim J, Young M, Robey PG, Wang CY and Shi S. Investigation of multipotent postnatal stem cells from human periodontal ligament. Lancet 364: 149-155, 2004

3. Tomokiyo A, Maeda H, Fujii S, Wada N, Shima K and Akamine A. Development of a multipotent clonal human periodontal ligament cell line. Differentiation 76: 337-347, 2008

4. Viñals F, López-Rovira T, Rosa JL and Ventura F. Inhibition of PI3K/p70 S6K and p38 MAPK cascades increases osteoblastic differentiation induced by BMP-2. FEBS Lett 510: 99-104, 2002

5. Ghosh-Choudhury N, Abboud SL, Chandrasekar B and Ghosh Choudhury G. BMP-2 regulates cardiomyocyte contractility in a phosphatidylinositol 3 kinase-dependent manner. FEBS Lett 544: 181-184, 2003

6. Hu Y, Chan E, Wang SX and Li B. Activation of p38 mitogenactivated protein kinase is required for osteoblast differentiation. Endocrinology 144: 2068-2074, 2003

7. Zhu W, Rawlins BA, Boachie-Adjei O, Myers ER, Arimizu J, Choi E, Lieberman JR, Crystal RG and Hidaka C. Combined bone morphogenetic protein-2 and -7 gene transfer enhances osteoblastic differentiation and spine fusion in a rodent model. J Bone Miner Res 19: 2021-2032, 2004

8. Janssens K, ten Dijke P, Janssens S and Van Hul W. Transforming growth factor-beta 1 to the bone. Endocrine Reviews 26: 743-774, 2005

9. Lee JY, Kim KH, Shin SY, Rhyu IC, Lee YM, Park YJ, Chung CP and Lee SJ. Enhanced bone formation by transforming growth factor-beta1-releasing collagen/chitosan microgranules. J Biomed Mater Res Part A 76A: 530-539, 2006

10. Zhao L, Jiang S and Hantash BM. Transforming growth factor $\beta 1$ induces osteogenic differentiation of murine bone marrow stromal cells. Tissue Eng Part A 16: 725-733, 2010

11. Lee KS, Hong SH and Bae SC. Both the Smad and p38 MAPK pathways play a crucial role in Runx2 expression following induction by transforming growth factor- $\beta$ and bone morphogenetic protein. Oncogene 21: 7156-7163, 2002

12. Ripamonti U, Ferretti C, Teare J and Blann L. Transforming growth factor- $\beta$ isoforms and the induction of bone formation. J Craniofac Surg 20: 1544-1555, 2009

13. Ochiai H, Yamamoto Y, Yokoyama A, Yamashita H, Matsuzaka K, Abe S and Azuma T. Dual nature of TGF-â1 in osteoblastic differentiation of human periodontal ligament cells. J Hard Tissue Biol 19: 187-194, 2010

14. Kaji H, Naito J, Sowa H, Sugimoto T and Chihara K. Smad3 differently affects osteoblast differentiation depending upon its differentiation stage. Horm Metab Res 38: 740-745, 2006

15. Sowa H, Kaji H, Yamaguchi $T$, Sugimoto $T$ and Chihara $K$. Smad3 promotes alkaline phosphatase activity and mineralization of osteoblastic MC3T3-E1 cells. J Bone Miner Res 17: 1190-1199, 2002

16. Kwok S, Partridge NC, Srinivasan N, Nair SV and Selvamurugan N. Mitogen activated protein kinasedependent inhibition of osteocalcin gene expression by transforming growth factor-beta 1. J Cell Biochem 106: 161169,2009

17. Ochiai H, Okada S, Saito A, Hoshi K, Yamashita H, Takato $\mathrm{T}$ and Azuma $\mathrm{T}$. Inhibition of insulin-like growth factor-1 (IGF-1) expression by prolonged transforming growth factor$\beta 1$ (TGF- $\beta 1$ ) administration suppresses osteoblast differentiation. J Biol Chem 287: 22654-22661, 2012

18. Chernausek SD, Backeljauw PF, Frane J, Kuntze J and Underwood LE. GH Insensitivity Syndrome Collaborative Group. Long-term treatment with recombinant insulin-like growth factor (IGF)-I in children with severe IGF-I deficiency due to growth hormone insensitivity. J Clin Endocrinol Metab 92: 902-910, 2007

19. Bernstein A, Mayr HO and Hube R. Can bone healing in distraction osteogenesis be accelerated by local application of IGF-1 and TGF- $\beta 1$. J Biomed Mater Res 92B: 215-225, 2010

20. Nakayama Y, Nakajima Y, Kato N, Takai H, Kim DS, Arai M, Mezawa M, Araki S, Sodek J and Ogata Y. Insulin-like growth factor-I increases bone sialoprotein (BSP) expression through fibroblast growth factor-2 response element and homeodomain protein-binding site in the proximal promoter of the BSP gene. J Cell Physiol 208: 326-335, 2006

21. Yang L, Zhang Y, Dong R, Peng L, Liu X, Wang Y and 
J.Hard Tissue Biology Vol. 23(1):9-14, 2014

Cheng X. Effects of adenoviral-mediated co-expression of bone morphogenetic protein-7 and insulin-like growth factor1 on human periodontal ligament cells. J Periodontal Res 45: 532-540, 2010

22. Walsh S, Jefferiss CM, Stewart K and Beresford JN. IGF-I does not affect the proliferation or early osteogenic differentiation of human marrow stromal cells. Bone 33: 8089, 2003

23. Jaiswal N, Haynesworth SE, Caplan AI and Bruder SP. Osteogenic differentiation of purified, culture-expanded human mesenchymal stem cells in vitro. J Cell Biol Chem 64: 295-312, 1997

24. Song IH, Caplan AI and Dennis JE. In vitro dexamethasone pretreatment enhances bone formation of human mesenchymal stem cells in vivo. J Orthop Res 27: 916-921, 2009

25. Yakar S, Courtland HW and Clemmons D. IGF-1 and bone:
New discoveries from mouse models. J Bone Miner Res 25: 2543-2552, 2010

26. Canalis E, Economides AN and Gazzerro E. Bone Morphogenic Proteins, their antagonists, and the Skelton. Endocrine Reviews 24: 218-235, 2003

27. Hong D, Chen HX, Xue Y, Li DM, Wan XC, Ge R and Li JC. Osteoblastogenic effects of dexamethasone through upregulation of TAZ expression in rat mesenchymal stem cells. J Steroid Biochem Mol Biol 116: 86-92, 2009

28. Canalis E and Delany AM. Mechanisms of Glucocorticoid Action in Bone. Ann NY Acad Sci 966: 73-81, 2002

29. Sun ZL, Fang DN, Wu XY, Ritchie HH, Bègue-Kirn C, Wataha JC, Hanks CT and Butler WT. Expression of dentin sialoprotein (DSP) and other molecular determinants by a new cell line from dental papillae, MDPC-23. Connect Tissue Res 37: 251-261, 1998 